\title{
International Standards in Vocational Education and Training for Financial Services Sector to Ensure Sustainable Development and Environmental Safety
}

\author{
Maria Sigova ${ }^{1, *}$, Inna Kruglova $^{1}$, and Antonina Ignatova ${ }^{1}$ \\ ${ }^{1}$ ANO HE International banking institute, 191023 Nevsky pr. 60, Saint-Petersburg, Russia,
}

\begin{abstract}
The article presents an overview of the Triple E Project developed by EBTN for the purpose to work out qualifications standards for finance services sector in the focus of sustainable development and environmental safety. The Triple $\mathrm{E}$ is based on the three instruments - European qualification framework and concept of learning outcomes (EQF), credit system (ECVET) and quality assurance (EQAVET) for vocational education and training. These three systems are the building blocks of European policy in vocational education and qualifications system with the task to strengthen the integration processes in the European educational area. They also take into account the concept of UNESCO in the field of education and sustainable development. Besides, the article traces the history of relations between educational providers, employers and public authorities in the Russian Federation in the context of setting requirements for learning outcomes and qualifications. The concepts of qualification, velocity of changes in educational standards, the establishment of a national system of qualifications of the Russian Federation, the emergence of professional standards are carefully analyzed. Current and potential problems in the assessment of qualifications are referred to. It is stressed that the volume of open data in the area of professional development, education and labor should be increased and the quality thereof significantly improved.
\end{abstract}

\section{Introduction}

The key idea of the contemporary economy, according to international and Russian strategies of development is a steady increase in the knowledge based economy. Scientific theories and best practice are the parent elements of this economy. A steady increase in the economy, based on the knowledge, can be provided only due to the high level quality of education. The contemporary economy has integrative nature therefore the present-day problem is the creation of international standards for higher and vocational education.

For several decades the entire system of higher education and vocational training in the Russian Federation has been undergoing the permanent and painful process of numerous reforms and adjustments. The educational system of the Former Soviet Union was closely

Corresponding author: sigovamv@ibispb.ru 
connected with its planned economy and the enterprises used to order a certain kind of specialists and the existing obligatory graduate placement scheme provided close connection between the country's educationalinstitutions and employers. After the FSU disintegration and the transition from planned to market- oriented economy, the above connection has disappeared. In the middle of 1990s Russia initiated the educational reform to meet requirements of the International Monetary Fund and immediately started to work out the Educational Standards. In 2003 Russia became part of the Bologna process with the aim to be also a part of European Higher Education Area (EHEA) thus facilitating international cooperation and academic exchange. To reach this goal Russian legislation was changed: instead of the former three level system "specialist degree - post-graduate degree - doctoral degree" the new system based on qualifications framework "bachelor's degree - master's degree - post-graduate degree - doctoral degree" was introduced, thus changing the award on specialty to award on qualification for each education level.

After two decades of reforms integration of the RF into EHEA a certain extent was implemented: the scope of academic exchange grew and international cooperation between educational providers accelerated. But a gap between educational content and employer's needs was rising because the majority of the Russian enterprises did not have either a power or an opportunity to change the content of educational programs. Therefore, they preferred onsite training for their employees by their own programs according to their own needs. To reduce the above gap, the RF introduced two new concepts: public professional accreditation (2011) and professional standard (2012).

One of the reason of educational reform was Russia's aspiration to join the World Trade Organization which was achieved in 2012, after nine years of being a part of the Bologna process. In addition to educational reform, the labor system was also changed, namely the National Qualifications Framework of the RF was implemented based on the principles of the European Qualifications Framework (EQF).

\section{International Standards in Vocational Education and Training}

The EQF [26] developed in the course of Bologna process, which is a process of integration of education systems of the European Union and European economic zone. EQF was developed as translation tool for communication and comparison between qualification systems of member-states and one of a number of tools for the education expanding and economy strengthening in EU.

The qualifications framework was created with purpose to compare qualifications awarded in different countries, to make correlative international educational programs, to include in qualifications elements both non-formal and informal learning. The EQF allows all education's stakeholders (students, education providers and employers) to compare the conferred qualifications in various countries and on different levels of educational system. Thanks to the Framework's explicitly formulated hierarchy of education and its stipulated system of levels.

In EQF adopted in 2008, the entire spectrum of existing qualifications is proposed to rank into eight levels. Every level defined by a set of descriptors indicating the learning outcomes relevant to qualifications at that level in any system of qualifications. Content of qualification is described in terms of the learning outcomes: knowledge, skills and competences and establishes the hierarchy of the qualification levels. Thus, for achieving the first level of qualification it is sufficient to have a basic general knowledge and skills allowing to work under direct supervision in a structured context. The EQF develops idea of three levels in higher education (bachelor, master, doctor), formulated within Dublin descriptors [7] and developed within Bologna process in the EHEA. Internationally the EQF is correlates with the 
International Standard Classification of Education (ISCED) first revealed by the UNESCO Institute of Statistics in 1997 and last revised in 2011[16].

The EQF was approved by the European Parliament in April 23, 2013. It is assumed that each newly created qualification will be designed taking into account the above EQF levels. But this is not a case yet. The EQF is implemented on national level. Until it will fully implemented by member-states, there will be no reference new qualifications with EQF. There are only 13 NQFs (three of which were developed in the United Kingdom) operating at present [9]. Twenty countries have referencing reports of implementation agreed with the EU Commission and 36 countries are cooperating within EQF.

The implication is that every European member-state is supposed to create a national qualifications framework, showing a certain degree of similarity of the existing system of education and qualifications with that of EU. This framework is an instrument which allows any national qualifications framework effectively enter in European system of vocational education and labor market. Presently not all European countries agree with the above which is caused either by weak systematic policy and information base or because of the absence of adequate consideration and financing from their respective governments.

Furthermore, some states are strongly biased towards their own systems of education, which confirmed their effectiveness for many years and therefore they do not hurry to reject them and introduce EQF levels which can seem to some of them not quite reasonable to accept. At the same time the number of states carry out sufficiently strong policy in this direction, in particular France, Malta, Ireland and Great Britain. It was in Ireland and Britain where the list of qualifications (The register of regulated qualifications) [29] was first developed, realizing EQF concept.

Let us turn to the concept of qualification. There are two contexts of understanding this concept in European educational policy. As job requirements "qualification" means "knowledge, aptitudes and skills required to perform specific tasks attached to a particular work position". Another meaning of the term "qualification" as a formal qualification: "the formal outcome (certificate, diploma or title) of an assessment process which is obtained when a competent body determines that an individual has achieved learning outcomes to given standards and/or possesses the necessary competence to do a job in a specific area of work". We point out that the concept "learning outcomes" has completely definite meaning as "set of knowledge, skills and/or competences an individual has acquired and/or is able to demonstrate after completion of a learning process, either formal, non-formal or informal".

There are two contexts of qualification concept in Russia too. According to Labour Code of the RF, qualification of employee is defined as "a level of knowledge, skills, professional attainment and work experience" [17]. According to the Federal Law "About Education at the Russian Federation", qualification is "a level of knowledge, skills, attainment and competence, characterizing the readiness to perform a certain type of professional activity"[27]. In our opinion, there is a problem of distinguishing between the terms "skills" and "attainment" in the Russian language [15]. Both terms are used in all editions of State Educational Standards of the RF, but in Professional Standards the term "skills" is only used.

Russia has also been designing its own NQF. In 2006 the Russian Union of Industrialists and Entrepreneurs (RUIE) set up the non-governmental organization "National agency of the qualifications development" (NAQD) to coordinate actions of organizations representing business community, to stimulate interaction between business and state bodies during formation of the NQF, to create the NQF, professional standards and the system of qualifications assessment and certification. In 2008 NAQD together with Federal Institute for Educational Development presented NQF of the RF, being almost identical to EQF, but having one level more. It is assumed, that NQF will be a part of National Qualification System of the RF, that will include sectoral qualifications framework, educational and professional standards, national assessment system of learning outcomes and certification [6]. In 2012 the 
Agency for Strategic Initiatives supported an entrepreneurial initiative "Development a national system of competences and qualifications" [5]. The road map for this initiative was designed in 2013, according to which the full implementation of national system of competences and qualifications should take place in 2015-2018. There are no data or reports as to the information whether the key performance indicators on this project were fully worked out. Only few reports for Krasnoyarsk Krai (2013) were published and the last reference to this project was in February, 2014. In April, 2014 the National Council under the President of the Russian Federation on Professional Qualifications was created with President chairing it and by its initiative Sectoral Councils on Professional Qualifications were created on the basis of the relevant sectoral employers' associations.

The legal bases for the level qualifications in Russia were developed in April, 2013. The order issued by the Ministry of Labor and Social Protection approves qualifications levels to develop projects for professional standards. The basis of this order is NQF for the RF worked out five years ago. Supplemented by description of the paths of achieving each level of qualification, i.e. education levels from the instruction on the first level qualification to the post-graduate and doctorate degree on the ninth level qualification. By EQF the sixth, seventh and eighth levels qualification correspond to qualification of bachelor, master and Ph.D. Respectively, while by NQF for the RF sixth and seventh levels qualification correspond to qualification of bachelor, specialist and master, the eighth level corresponds to qualification of specialist and master, and the ninth level corresponds to qualification of Ph.D.

In Russia, the requirements for learning outcomes, needed to obtain a certain level of qualification, are formulated according to the State Educational Standards being developed since 1994 and over three editions of those standards have been developed for the last 20 years. As was mentioned above, in European education policy results of learning are described in terms of knowledge and skills, and the ability to implement them in practice as competence. In curricula it is formulated as details the learner will know and can or able to do. Some of the member-countries also have educational standards, for example, the educational standards in Ireland are designed in accordance with the National Qualifications Framework of Ireland, and they contain generic requirements for the level of learning outcomes.

In Russia, requirements for learning outcomes started be formulated in the second edition of State Educational Standards (2000) with the structure of "to know - to able to do - to possess". The third edition of State Educational Standards in the requirements for learning outcomes introduced the concept of competence (2010) divided into two groups - general culture competences and professional competences. This standard establishes connection between competences and number of certain disciplines. In the content of State Educational Standards " $3+$ edition" (2014-15) the third group of competences was added - the general professional competences but there is no established disciplines in the standard, and the structure of describing competence as "to know - to be able to do to possess" disappeared. Generally speaking, the quantity requirements to content of learning outcomes decreases with each new standard.

In spite of serious work being conducted by state and commercial institutes to establish the qualifications framework, and especially their gradation along eight levels, proposed by the $\mathrm{EQF}$, the desired unity of understanding and its realization is lacking. There is a certain clarity of requirements for design a higher education qualification since these requirements are formulated in Federal State Educational Standards, but there is no such clarity for the vocational qualification. Since the requirements to correlate vocational qualification with the professional standard are not yet legislatively established in RF at the legislative level.

In the RF requirements for employees set out in the Qualification Catalogs and Wage Rate books for jobs and professions, approved in 1998 and later. They contain job descriptions, minimum necessary knowledge and qualification (level of education and experience). In December, 2012 the Labor Code of the RF was supplemented with a new article 195.1, 
introducing the concept of professional standard in the Russian law practice. In April, 2013 several orders were issued containing rules and methods for the development of professional standards and the model of professional standard and special computer software "professional standard" were designed.

As far as the Russian vocational education is concerned, work here is conducted at two levels. On the one hand, at the level of professional associations as NAQD. On the other hand, the Ministry of Labor and Social Protection of RF officially (at the state level) asserts the developed professional standards and introduces them into the system of qualifications, reference books and registers.

It's premature assert that the educational standards (approved by the Ministry of Science and Education of RF) and professional standards (approved by the Ministry of Labor and Social Protection of RF) have the common denominator even despite the fact that real developers of standards often come out of education providers or academic methodological associations.

If the state educational standards are designed by Academic Methodological Associations, the professional standards are designed by employers' associations and some interested enterprises sometimes with participation of academic institutions. In April, 2014 the Ministry of Labor approved the State Program "Promoting employment of the population" after the realization of which conditions should be created to improve quality of workforce and to raise its professional mobility by implementation of professional standards. Standards could be developed by initiative of employers at their own expense or at the expense of the federal budget focusing on the priority areas of economy. According to this Program during 2014-15 800 professional standards should be designed but by the September 2015 only 471 standards were approved. Currently, there are 40 organizations indicated in the registry of professional standards as developers thereof including 10 private companies, 16 state educational providers, one private educational provider, 17 employers' associations and a few government agencies and institutions. Despite the fact that the number of participants taking part in the standards development exceeds their number in the respective registry the absence of open data in machine-readable format makes it hard to analyze who is actually responsible for the content of the standards.

The structure of professional standard contains a number of labor functions related with a certain position, which are made clear by description of necessary knowledge and skills for carrying out specific labor actions. As opposed to educational standards, which use "knowledge - skills - attainment" structure for learning outcomes, professional standards refer to requirements for an employee to possess necessary knowledge and skills for carrying out specific labor actions. The chosen structure meets international requirements to learning outcomes and qualification. According to the plan of the Ministry of Labor, these professional standards should create a base for the contents and structure of professional education to comply with requirements of labor market. The Federal Law "About Education in the Russian Federation" in sub-section 7 of Art. 11 Federal State Educational Standard (sub-section is entered after 2009), demands to consider provisions of the corresponding professional standards when developing educational standards.

The Ministry of Labor has a detailed plan for development of professional standards with [6] a section in this plan about "implementation of the mechanism of a professional qualification assessment on the basis of the professional standards", which forms basic rules for adopting a bill of an independent assessment of professional level of employees' qualification as of the first quarter 2015. According to this plan, the Assessment and Certification of Qualifications Centers (ACQC) should be formed since the third quarter of 2014. In fact, those Centers were created by RUIE and NAQD initiative already in 2009. In the same year the Ministry of Education for the RF approved the Provisions on the Formation of an Independent Assessment of the Quality of Vocational Education and after that some 
Centers were created. Unfortunately, there is no unified register of these Centers on the website of NAQD at the present moment. According to RF Government Decree №881-p from 14 May 2015, there is 36 ACQC and 3680 individuals were certified in 2015. There isn't published any concrete information about this certificates, that allow analyze present situation about qualifications and their assessment.

It is essential that ACQC exercise their authority on the basis of a contract with the State Council (from NAQD) for certain financial compensation [6].

According to our analysis of a number of professional standards it is possible to assert that their developers correlate qualifications and EQF levels (predominantly in the professional standards they use levels 5-8). However, in our opinion, it is early to speak about intelligible and transparent relationship of Russian professional standards, qualifications and educational programs with those of other states.

One should add that in spite of indicated problems Russia undertakes active efforts in the right direction. Recent interest to educational system among Russian enterprises has grown as well as possibility to influence it in accordance with the real needs of the labor market. It is difficult to say that this phenomenon has general and mass character. Number of enterprises prefer to create their own vocational education centers to training staff according they own principles and in this case the common concept field of continues professional development could be missed.

There are several problems concerning the interaction between government, education providers and labor market:

- insufficiency of open data on all areas of work;

- published data are not adapted for computer processing and analysis;

- there is no traced interrelation between plans and their realization;

- there is no traced interrelation with data sources and calculations of the quantitative and

- qualitative performance for indicators specified in road maps, programs, etc.

- For example, Research Institute of Labor and Social Insurance should publish not only a text of a road map or an events plan, but these documents have to contain references to calculations of the chosen indicators with references to sources of statistical data (for example, by number of workers in different economy sectors, or graduates on particular specialties). Furthermore, it is necessary to add references to reports on realization of the planned actions in the same documents. Another example, the Register of developers of professional standards mentioned earlier, may contain attributes as "type of property" or "region", and it should be available in a machine-readable format, the same concerns also the data on professional standards.

- There is a number of disputed issues about an idea of assessment of qualification, offered by RUIE and NAQD.

- One of the issue is a distinguish between training and certification. According to NAQD it is not enough for a graduate to be assessed by education provider to earn a qualification. One disputed issue is an awarding body. Verification of qualification should be independent from learning process. Idea of NAQD is to divide training from verification by distinguish this function between two independent body - one is an education provider, other is an awarding body (ACQC). But in Russian practice frequently education provider wins the contest and it occurs as an ACQC. That means there is no any difference between training and awarding bodies. As other option, Triple E standard offers a concept of "Chinese wall" between training and verification. Education provider must provide functional independency and separation persons responsible for training and examination. This separation must be granted by documented procedure and must be verifiable by external auditors. In this case there is no necessity for ACQC. 
- Another issue is a type of certificate. After finishing 6 to 9 levels qualification the state diploma is conferred. In the case of certification by the respective ACQC, graduates should also be conferred the state diploma. For now, ACQC gives a certificate of voluntary certification. What should be the difference between diploma and a certificate, if the educational provider and the ACQC is the same organization?

- The third issue is the accreditation of the ACQC. At present accreditation of educational providers is done by Government. Relationship between NAQD and the ACQC are built on the contract base, and in this case the ACQC cannot be quite independent in its assessment.

- Another section of the comprehensive plan for development professional standards $[6,18]$ contains the clause "revision concerning information resource for professional development (information on staffing, careers, opportunities for education and employment on the basis of existing information resources"). According to the clause, this kind of information resource covers the period of 2015-16. For now, in Runet there are two information resources on the subject of professional standard - one is inactive standartprof.ru and another one is an active profstandart.rosmintrud.ru. The last one does not publish information on staffing, careers, opportunities for education and employment. In EU this kind of information is usually published in national qualification frameworks resources.

- The problem of lack of interaction between education providers and employers can be solved by creation of effective communication technologies, primarily public information databases and environments that will effect a transfer of concepts and requirements among stakeholders, as well as create a database of publicly available methods to assess the professional qualifications.

- During the European integration process there is appeared a large number of different projects for development of sustainable economy through education policy and the EQF is one of them. There are some distinct projects and tools which are important for vocational education. One of the is the European Credit system for Vocational Education and Training (ECVET). ECVET being developed with the support of the European Commission since 2008 till present $[10,11,13]$. ECVET as a recommendation is ready. It's full implementation in EU is still in process.

- ECVET is created to ensure the mechanism of accumulation and transfer of learning outcomes. The effective work for implementation of international vocational qualifications based on the principles similar to the European Credit Transfer and accumulation System (ECTS).

ECVET tools [11] have been developed in order to increase the geographical mobility of trainees, to create the conditions for obtaining the qualifications in the educational organizations and the practical instruction on the territory of different states and to ensure the procedure of conducting this instruction. ECVET determines the minimum of the documented information, necessary for organizing the mobility of trainees [2]:

- the learning outcomes: the data about education, skills and competences, accumulation and transfer of learning outcomes connected with the professional sphere and the learning profiles, the criteria of comparability, the establishment of the equivalence between units;

- the process of learning: synchronization or sequence of studying curricula, units in ECVET format, process of assessment and verification;

- $\quad$ the organization of financing the mobility.

Besides this, ECVET established the set of rules and principles for unit's accumulation, which was learned by formal, non-formal and informal learning, and their transfer for the purposes of the qualifications acknowledgement. In ECVET the qualifications are described in terms of learning outcomes with the attribution of ECVET points. 
Credits in the ECVET are determined on the basis [2,3]:

- $\quad$ the object of learning (theory, practice, base skills, the general education);

- $\quad$ the learning outcomes (knowledge, skills, competence)

- the place of learning (in class, apprenticeship, on the job training, at home),

- $\quad$ the context of learning (formal, non-formal, informal);

- $\quad$ the duration of learning (years, months, semesters).

Every stakeholder, student, education provider or employers can use ECVET to understand verification procedure for professional qualifications, which was obtained by studying in different countries.

The system of transfer and accumulation units for higher education works for decades (projects Tempus, Erasmus and other forms of international academic mobility), but exchanges in vocational education is not wide spread in RF. As far as we know, there are no procedure by including learning outcomes of non-formal and/or informal in regarding qualifications in RF at the present moment. There is kind of preparation legislative basis for the launching the above procedure. However, it concerned only e-learning (technology of distant learning).

Recently Russian enterprises actively use training, role games, teambuilding and similar methods of non-formal learning as the policy of professional development. However, as in continuous professional development of employees according to curricula created by enterprise, it is hard to find any accumulation and transfer system for credits of learning outcomes.

The main point to establish good vocation education is a quality assurance. In EU were created a recommendation for quality assurance in vocation education and training. European Quality Assurance in Vocational Education \& Training (EQAVET) being developed by the European Commission since May 2001 till present [14]. EQAVET is a very large union [12] of representatives of educational committees and ministries of the European countries, candidates- countries and countries of European economic zone, social partners - commercial associations and trade unions, and also scientists from the European Commission and the European Center for the Development of Vocational Training (Cedefop).

As quality assurance tool, EQAVET is based on the Standards and Guidelines for Quality Assurance in European Higher Education Area (ENQA) and Common quality assurance framework (CQAF). The EQAVET's aim is to find and implement the most effective procedures of quality assurance in VET.

There are two levels of development quality assurance procedures:

- $\quad$ for national level EQAVET develops Quality Assurance for VET-system [22],

- $\quad$ for VET providers EQAVET develops Quality Assurance for VET-provider [21].

There was developed the web-application, which allows stakeholders to use EQAVET as a management tool for quality assurance. As a basis PDCA cycle is used, which consists from four stages - planning, implementation, assessment and review. One can find for each stage tentative descriptors, making it possible to evaluate whether the above stages correspond to the requirement of, and if corresponds, then to what degree. All tentative descriptors are accompanied by examples of the best practice of educational policies and/or organizations. Furthermore, methodology EQAVET is presented in two versions - for those, who only plan to build system of quality assurance (complete cycle) and for those, who want to assess the already existing system of quality assurance (stages of assessment and review) with the stress on data collection and analysis.

The total purpose EQAVET is to increase the culture of quality assurance of the educational services in the European Union and beyond, and also to stimulate the support of national policies of the states for improvement of quality in vocational education. 
In the Russian Federation the attention is paid to quality assurance and control of education, including the quality of vocational education. State institutions such as the Federal Service for Supervision in Education and Science (Rosobrnadzor) and the Federal State Budgetary Institution "National Accreditation Agency" deal with the issues of verification of education quality.

The role of the public accreditation of educational programs is constantly growing. In Russia there is a number of agencies for the public accreditation of the educational programs, for example, non-governmental organizations "The National Center for Public Accreditation" (Yoshkar-Ola) or "The Agency for Quality Assurance in Higher Education and Career Development (AKKORK)" (Moscow). The national agency AKKORK formed the State Council for Independent Quality Assessment of Vocational Education consisting of two commissions: the Commission for independent assessment and certification of qualifications and the Commission for professional accreditation of qualification in VET. Some educational programs undergo professional accreditation by the international accrediting agencies, but the practice of professional accreditation of educational programs for vocational education is not yet wide spread in RF.

There are a few sectoral projects, which implement principles of quality assurance, transfer and accumulation of credits, or translate descriptors of qualifications framework to certain field. There are a few such projects for financial services sector (FSS) in European Union. For quality assurance in VET for FSS there is a QUALES project (2014-2015), for translation descriptors of qualifications framework there is a FIRST project (2009-2011), synthesizing approach is presented in Triple E project (2013-2015). We examine the last one.

The Triple E project was implemented by the European Banking \& Financial Services Training Association - EBTN) [31] in the period from October 1, 2013 till September 30, 2015 with the support of the European Commission and Leonardo da Vinci Programme.

An international not for profit association European Banking \& Financial Services Training Association A.i.s.b.l. (initially European Banking Training Network) unites 26 full members - education providers and employees' associations in FSS at the European Union and beyond, including the Russian Federation. There are two Russian organizations is full EBTN members presently - Banking Institute of the Association of Russian Banks (Moscow) and International Banking Institute (St Petersburg). Furthermore, EBTN includes 17 associate members, which provide financial education and training worldwide. EBTN is registered and located in Brussels (Belgium).

The main objective of EBTN is to represent the interest of the leading European bank training organizations and provide condition for improving professional culture in FSS through training and education both in the European Union and beyond its limits. To achieve this objectives EBTN leads various projects, most of them initiated by European Commissions, with the purpose to implement education projects of EU taking into account the specific character and needs FSS.

Triple E is aimed "to gather the main tools and recommendations related to existing modern EU qualifications and turn them into one integrated standard which is both aspirational and feasible for wider application in FSS" [8]. Those tools are - the European Qualification Framework (EQF), the European Credit system for Vocational Education and Training (ECVET) and European Quality Assurance in Vocational Education \& Training (EQAVET). They are the cornerstones of contemporary policy in the sphere of vocational education and system of the qualifications of the

European Union. Taking into account the interest to vocational education for FSS, EBTN initiated the project for adaptation and propagation of European Union policy among financial and banking educational providers and associations.

The primary task of the project is to develop the quality standard and guidelines for qualifications in the European financial services sector on the basis of the above tools and to 
use this standard in the field of financial services. The project aims to strongly contribute to development of sectoral qualifications that will offer more flexibility, mobility and lifelong learning opportunities for the employees and employers of the sector. Moreover, the project supports the quality improvement of training systems through the development of innovative European Guidelines for the definition of professional qualifications in terms of learning outcomes, with the attribution of ECVET points, EQF level and according to quality assurance (EQAVET) criteria.

Triple E strives [8]:

1. To ensure comprehensive analysis and assessment of the best practices to design, development and realization of qualifications system for FSS.

2. To develop guidelines for designing sectoral qualification system in terms of learning outcomes (EQF), taking into account transfer of ECVET units and in compliance with EQAVET recommendations.

3. To create the quality standard, including criteria and tools for assessment on the basis of European system of credit transfer for the qualifications of vocational education for FSS.

4. To test best manuals and guidelines for developing the Triple E-based qualifications and standards of quality for the application by Triple E.

During teamwork of educational providers, employer's associations and other stakeholders EBTN developed the Triple E guidelines, which set the requirements for the qualifications of Triple

Guidelines were introduced for all EBTN members and interested stakeholders 24, September 2015. As an example, EBTN applied this standard for qualification European Foundation Certificate in Banking (EFCB).

"Our ambition is that the "Triple E" qualification standard will set up the top quality benchmark for the sectoral qualifications of financial services in the years to come. The standard is to bring a new dimension of cooperation and trust in the financial services sector. We want the "Triple E Qualifications" to be relevant for the sector, transparent for all users, reliable to deliver what they promise, supported and applied by people and organizations" [31].

Within the project framework several stakeholders were offered two surveys, on basis of which the number of recommendations regarding the qualifications of Triple $\mathrm{E}$ was accomplished [8]:

- $\quad$ to inform stakeholders about the above three tools;

- $\quad$ to use quality management system based on the standards of a ISO 9000 series, the national qualifications framework and accreditation procedure of VET providers;

- $\quad$ to use ECVET procedure without any adjustments and amendments;

- $\quad$ to involve stakeholders in design and assessment of qualifications, considering the interests of labor market and employers;

- $\quad$ to provide access to information about qualifications, learning outcomes, criteria of assessment;

- qualifications in FSS can be obtained by assessment of non-formal and informal learning, and consistent criteria of their assessment should be indicated;

- $\quad$ each qualification should be revised and updated with due consideration of the latest achievements
- to inculcate
development
$(\mathrm{CPD})$
elements of
continuous
professional

Triple E standard consists from three blocks [32]:

1. Infrastructure (EQAVET)

2. Values 


\section{Content (EQF, ECVET)}

The Standard states that quality assurance of the qualification infrastructure is achieved by following four steps: first, it is necessary to carry out the accreditation of educational organization at both the regional level and with the attraction of the international accrediting agencies. ISO certification and sector accreditation can be referred to as positive examples. Second, special attention should be paid to the unlimited access to the information about the qualification for the public. All the necessary information about the qualification should be published - lists of the required documents, procedures and actions, financial information, zones of responsibility and duration of learning. Third, the sectoral qualification councils should be created, which will provide accreditation both qualifications and educational provides. And fourth, all existing qualifications should be correlated with the EQF.

The content of qualifications should be specified in terms of learning outcomes knowledge, skills and competences, and the size of qualification should be at least 50 hours. However, the indicated time must not be spent only in auditoriums. Qualifications can include the wide spectrum forms of learning. The size of each unit should comprise at least 10 hours and unit must have appropriate educational methodical documentation. EBTN introduces the Triple E concept of points: 1 triple (1 VET of credit) equal 10 hours of training. The amount of hours of a constant professional development (CPD) for each qualification should comprise at least 10 hours per year and is validated once every three years. The learning should not contain only on the job training or only self-assessment. A half of assessment could be a written report with confirmed evidence, or if there is no one, it should be confirmed by a third party. To assess the remaining 50 percent of knowledge obtained the accepted methods of assessment should be worked out taking into account the flexible approach to the methodology of evaluation.

Triple E establishes 10 values, relating both to the content and to the infrastructure of qualification. Qualifications must be relevant, transparent, reliable, impartial, flexible, effective, and creative, they should be part and parcel of professional activity, support the idea of lifelong learning and the application of knowledge in practice.

Since the objective of the standard is promotion information about EQF, ECVET, EQAVET values, its application by local institutions, i.e. by educational providers and by the associations of financial organizations, will contribute introduction into practice principles of the international educational policy into daily activity of organizations.

\section{Conclusions}

Attention, paid by the EBTN to the designated topic impels us as the members of association, to realize given principles in practice, to analyze the demands of the interested parties, to design programs on the basis of the proposed standard principles, to study the opinions of trainees and employers and, on the basis of the obtained data, to give feedback to EBTN and to Triple E developers.

This way - the standard, approval, recommendations for improvement, correction - the cycle of a constant improvement will be accomplished, which ultimately leads to an increase in quality of educational services, qualifications, and, finally, to economic growth and sustainable development and to an increase in the social stability and environmental safety.

Following the precise stages, i.e. standards, their approval, recommendations for their improvement, amendments and adjustments will help to go through the cycle of constant refinement which in the final analysis will lead to a rise in the quality of educational services and professional qualifications and thus to the growth of the economy, sustainable development and increasing social stability. 


\section{References}

1. Information on http://www.ebtn-triple-e.eu/corsi

2. N. M. Aksenova, O. N. Oleynikova,Kazan Pedagogical Journal, 3(104), 33-46 (2014)

3. N. M. Aksenova, E. V. Sartakova, Bulletin of the Tver State University. Series: Pedagogy and Psychology, 3, 122-134 (2014)

4. Information on http://www.edu.ru/db/portal/spe/index.htm

5. Information on http://asi.ru/npi/nskk/

6. Development of the National Qualifications Framework: a collection of pre-normative documents (Publishing House "Pen", Moscow, 2014)

7. Information on http://www.tcd.ie/teaching-learning/academicdevelopment/assets/pdf/dublin_descriptors.pdf.

8. Information on http://www.ebtn-triple-e.eu/corsi

9. EC. Find and Compare Qualifications Frameworks, information on https://ec.europa.eu/ploteus/en/compare

10. ECVET projects, The Education, Audiovisual and Culture Executive Agency (EACEA), 2010-2014 information on http://www.ecvet-projects.eu

11. ECVET toolkit, Nationale Agentur Bildung für Europa beim Bundesinstitut für Berufsbildung (NA beim BIBB) information on http://www.ecvet-toolkit.eu/

12. EQAVET European Quality Assurance in Vocational Eduction and Training. - EQAVET Secretariat - Quality and Qualifications Ireland (QQI) information on www.eqavet.eu

13. European ECVET Network information on http://www.ecvet-team.eu/en

14. From ENQA-VET to EQAVET German Reference Point for Quality Assuranse in VET information on https://www.deqa-vet.de/en/From-ENQA-VET-to-EQAVET-2190.php

15. E.P. Ilyin, Questions of psychology, 5, 1984

16. International Standard Classification of Education. - UNESCO Institute for Statistics, 2011 information on http://www.uis.unesco.org/Education/Documents/isced-2011-ru.pdf

17. Labor Code of the RF

18. A.N. Leibowitz, I.A. Voloshin, A.S. Perevertajlo, O.D. Pryanishnikova An independent evaluation and certification of qualifications: Collection of documents and materials (Publishing House "Pero", Moscow, 2014)

19. N. Mospan, Continuing professional education: Theory and Practice, 1-2, 38-41 2014

20. O. G. Nefedova, Accreditation in Education, 8, 62 (2006)

21. Quality Assurance for VET-provider - EQAVET information on http://www.eqavet.eu/qc/gns/home.aspx

22. Quality Assurance for VET-system - EQAVET information on http://www.eqavet.eu/qa/gns/home.aspx

23. M. B. Sinyagovskaya, The world of science, culture and education, 5, 53-55 (2013)

24. Terminology of European education and training policy-a selection of 130 key terms

(CEDEFOP, Luxembourg, 2014)

25. The European Banking \& Financial Services Training Association information on http://www.ebtn-association.eu

26. The European Qualifications Framework, European Commission information on $\mathrm{http}: / /$ ec.europa.eu/ploteus/search/site?f[0]=im_field_entity_type\%3A97 